\title{
Association between Unmet Needs for Informal support and Diabetes-related Distress among People Living with Type 2 Diabetes in Vietnam: A Cross-sectional Study
}

\section{Diep Thi Khong ( $\nabla$ diepkhongtbmu@gmail.com )}

Thai Binh University of Medicine and Pharmacy: Thai Binh Medical University https://orcid.org/00000002-7410-5927

\section{Bai Nguyen Xuan}

Thai Binh University of Medicine and Pharmacy

\section{Cuong Le Duc}

Thai Binh University of Medicine and Pharmacy

Tine Gammeltoft

University of Copenhagen

\section{Jens Søndergaard}

University of South Denmark

\section{Dan Wolf Meyrowitsch}

University of Copenhagen

Ib Christian Bygbjerg

University of Copenhagen

Jannie Nielsen

University of Copenhagen \& Emory University

\section{Research article}

Keywords: Diabetes-related distress, type 2 diabetes, unmet needs for informal support, Vietnam

Posted Date: October 7th, 2020

DOl: https://doi.org/10.21203/rs.3.rs-86172/v1

License: (1) This work is licensed under a Creative Commons Attribution 4.0 International License. Read Full License 
Version of Record: A version of this preprint was published at BMC Public Health on August 11th, 2021. See the published version at https://doi.org/10.1186/s12889-021-11562-6. 


\section{Abstract}

Background: Diabetes-related distress (DRD) in people with type 2 diabetes (T2D) is associated with reduced quality of life. Lower levels of DRD were found in people who received informal support. The prevalence of T2D in Vietnam is rapidly increasing. Yet, the prevalence of DRD and its association with informal social support have not been investigated. The present investigate the prevalence of DRD and its association with unmet needs for informal support in people with T2D in Vietnam.

Methods: A total of 806 people, age ${ }^{3} 40$ years, diagnosed with T2D in Thai Binh, Vietnam, completed a questionnaire-based cross-sectional survey. DRD was self-reported, based on the Problem Areas In Diabetes scale 5 (PAID 5). We assessed 6 types of unmet needs for informal support from family/friends/community including: (i) Transport and company when visiting health facilities; (ii) Reminders to take medication; (iii) Purchase and preparation of food; (iv) Reminders to engage in physical exercise; (v) Emotional support; and (vi) Financial support. Multivariable logistic regression was used to model DRD as an outcome of each type of unmet need for informal support, and as an outcome of the number of unmet needs for informal support, adjusted for three sets of covariates.

Results: The prevalence of DRD in people with T2D was 50.0\%. Odds for DRD were higher among those who had unmet needs for emotional support and financial support as compared to those with met needs (OR=2.59, Cl95\%: 1.19-5.63 and OR=1.63, CI95\%: $1.10-2.40$, respectively). People who had more than one type of unmet need was not a higher risk of DRD as compared to those with only one type of unmet need.

Conclusions: Half of the people with T2D had DRD. DRD was associated with unmet needs for emotional and financial support. The findings suggest that in order to prevent or reverse DRD, family members and others providing informal support should be included in health programs and interventions targeting people with T2D in Vietnam and similar settings.

\section{Background}

The prevalence of people with T2D is increasing rapidly in Vietnam [1]. Though diabetes-related distress (DRD) is associated with poor control of diabetes and decreased quality of life, little is known about DRD and determinants associated with this condition in Vietnam. DRD is defined as stressful feelings associated with the challenges of managing diabetes, such as feeling overwhelmed by the requirement of self-management through adherence to diet, exercise, and medical care; or worrying about complications related to having diabetes $[2,3]$.

Previous studies have showed that DRD is associated with reduced quality of life [4,5]and poor adherence to dietary advice and medications in people with type 2 diabetes (T2D) [6]. In contrast, lower levels of DRD are seen in people who reported having social support in following a diet, taking medicine, exercising, testing blood glucose levels, and handling feelings about diabetes [7, 8]. Other studies showed that age, gender, and socio-economic factors as well as duration of diabetes and general health status 
are associated with DRD and with increasing levels of need for support, including informal support [712]. Social support is understood as help provided by family, friends, neighbors, relatives, and other informal care givers, and includes different areas of assistance, such as informational, emotional, companionship, and practical help [13-15]. Unmet needs for informal support can be defined as inadequate amount of help received from informal sources in relation to activities of daily living [16].

DRD is common in people with diabetes. Results of a meta-analysis including 55 studies from high- and middle-income countries showed that more than one-third of people with T2D had DRD [2], while a study conducted in 17 countries, including India and China, found that $45 \%$ of the people with diabetes had DRD [17]. In South-East Asia, a cross-sectional study of Malaysian adults with T2D, found that $50 \%$ had DRD [18], while a study from China showed that $23 \%$ of people with T2D had moderate DRD and $19 \%$ had a high level of DRD [19].

To assess the prevalence of DRD and investigate the associations with informal social support in a Vietnamese setting, we conducted a cross-sectional study among people with T2D .

\section{Methods}

\section{Study population, setting, and recruitment}

This cross-sectional survey collected self-reported questionnaire-based data from people with T2D in Thai Binh province, Vietnam, from December 2018 to February 2019, who had been diagnosed with T2D after the age of 40. Thai Binh is a rural province in the northern part of Vietnam and covers an area of $1,542 \mathrm{~km}^{2}$, with a population of $1,860,447$ people (2019). The province is divided into seven districts and one major city. Two of these districts, Quynh Phu district and Vu Thu district in the northern and southern parts of the province, respectively, were purposively selected for the present study. From a total of 68 communes in Quynh Phu district and Vu Thu district, we purposively selected four communes in each district as study areas. Two communes had the highest number of T2D people, while the two other communes were neighboring communes of the two selected communes, and convenient for data collection.

We recruited a total of 963 individuals, who resided in the eight selected communes and who were identified as having been diagnosed with or treated for T2D at three district hospitals in Vu Thu and Quynh Phu. Among them, 37 (3.8\%) refused to participate, and 78 (8.1\%) did not stay at the address reported to the hospital or had moved away by the period of data collection. A total of 848 people participated in the cross-sectional survey. Among these, 42 individuals were excluded from the data analysis because they were diagnosed with T2D before the age of 40 or did not remember when they were diagnosed. A total of 806 participants were eligible for the analyses.

\section{Data collection}


To collect data, we trained 16 village health workers from 8 selected communes at a 2-day workshop followed by 1-day field-based training. For the interviews, participants with T2D were contacted by mobile phone or via a personal visit. After the oral and written outline of the project was explained, persons agreeing to participate were asked to sign a consent form. The interviewer conducted the interview faceto-face, using a structured questionnaire (eight domains, 176 questions, including questions about emotional distress and informal support). No other persons were allowed to participate in or observe the interview session. All the participants were interviewed in their home.

\section{Outcome variable}

DRD was determined based on the short form of Problem Areas in Diabetes scale 5 (PAID 5) [20], containing five questions: 1) Feeling scared when you think about living with diabetes; 2) Feeling depressed when you think about living with diabetes; 3 ) Worrying about the future and the possibility of serious complications; 4) Feeling that diabetes is taking up too much of your mental and physical energy every day; and 5) Coping with complications. Answers were scored at five levels: not a problem (0 points), minor problem (1 point), moderate problem (2 points), somewhat serious problem (3 points), and serious problem (4 points). Thus, the total score can range from zero to 20 , and DRD was defined as a total score of $\geq 8$ points [20].

\section{Exposure variables}

We chose 6 unmet needs hypothesized to be associated with diabetes distress as these needs are associated with management and requirements for diabetes [9, 21]. Unmet needs for informal support were determined by asking 6 questions to people with T2D related to the extent they experienced support from family/friends/community regarding: (i) Transport and company when visiting health facilities; (ii) Reminders to take medication; (iii) Purchase and preparation of food; (iv) Reminders to engage in physical exercise; (v) Emotional support; and (vi) Financial support related to any of the above-mentioned items. Answering options were: 1) I receive too little support: 2) I receive adequate support; and 3) I receive too much support. For each item, unmet need for the support was coded as a binary variable with "I receive too little support" coded 1, whereas the other answering options were coded as no unmet need for support, 0 . We also created a variable for the total number of unmet needs, categorized as $1,2,3, \geq 4$ unmet needs.

\section{Covariates}

Demographic and socio-economic characteristics including sex (man, woman); age group (40-49 years, 50-59 years, 60-69 years, and $\geq 70$ years); marital status (single, living with spouse, not living with spouse/divorced, or widowed); occupation (unemployed/stays at home, farmer, small trade business/worker/government employee/private company, and retired); size of household (one member, i.e. living alone, two members, 3-4 members, and $\geq 5$ members); self-reported economic status of the household (poor, medium, and wealthy); self-reported physical health (poor, fair, and good); and duration of diabetes ( $<5$ years, $5-10$ years, and $>10$ years).

\section{Statistical analysis}


The descriptive characteristics of people with T2D stratified by DRD status are presented as frequencies. Chi-square tests were performed to compare the frequency of DRD by demographic, socio-economic, and health-related characteristics. Statistical significance level $p<0.05$ was used. We used logistic regression to model DRD as an outcome of each unmet need for informal support to manage diabetes, and as an outcome of total number of types of unmet needs for informal supports. All models were adjusted for age, sex, and household socio-economic status (model 1). As a next step, we further adjusted for selfreported physical health (model 2). Lastly, we also included adjusted for marital status and number of coresiding household members. Results are presented as odd ratios (OR) with 95\% confidence interval $(95 \% \mathrm{Cl})$. Data analyses were performed using SPSS (IBM Statistical Package for Social Science software) version 22.

\section{Results}

\section{Demographic, socio-economic, and health-related characteristics of people with diabetes-related distress}

Characteristics of the people with T2D stratified by DRD status are presented in Table 1. Overall prevalence of DRD was $50.0 \%$. Prevalence of DRD differed by statictically significant by following determinants; sex (59.1\% vs. $39.9 \%$ in women and men, respectively; marital status (single [68.4\%], living with spouse [47.4\%], not living with spouse/divorced [53.3\%] and widowed [55.2\%]); occupation (unemployed/stays at home [64.3\%], farmer [57.4\%], small trade business/worker/ government employee/private company [42.9\%] and retired [36.8\%]); self-report of economic situation of household (poor[74.7\%], medium [47.5\%] and wealthy [39.7\%]); and self-report of physical health (poor[64.9\%], fair [44.9\%] and good[26.7\%]). 
Table 1

Diabetes-related distress according to demographic, socio-economic, and health-related characteristics

\begin{tabular}{|c|c|c|c|c|}
\hline \multirow[t]{3}{*}{ Characteristic } & \multirow[t]{3}{*}{ Overall } & \multicolumn{2}{|c|}{$\begin{array}{l}\text { Diabetes-related } \\
\text { distress }^{1}\end{array}$} & \multirow{3}{*}{$\begin{array}{l}p \\
\text { value } \\
\left(\chi^{2}\right. \\
\text { test) }\end{array}$} \\
\hline & & YES & NO & \\
\hline & & $\begin{array}{l}\text { Number } \\
\text { (\%) }\end{array}$ & $\begin{array}{l}\text { Number } \\
(\%)\end{array}$ & \\
\hline All & & $\begin{array}{l}403 \\
(50.0)\end{array}$ & $\begin{array}{l}403 \\
(50.0)\end{array}$ & \\
\hline \multicolumn{4}{|l|}{ Gender } & \multirow{3}{*}{$\begin{array}{l}< \\
0.001\end{array}$} \\
\hline Men & $\begin{array}{l}381 \\
(47.3)\end{array}$ & $\begin{array}{l}152 \\
(39.9)\end{array}$ & $\begin{array}{l}229 \\
(60.1)\end{array}$ & \\
\hline Women & $\begin{array}{l}425 \\
(52.7)\end{array}$ & $\begin{array}{l}251 \\
(59.1)\end{array}$ & $\begin{array}{l}174( \\
40.9)\end{array}$ & \\
\hline \multicolumn{4}{|l|}{ Age group } & \multirow[t]{5}{*}{0.73} \\
\hline $40-49$ & $42(5.2)$ & $19(45.2)$ & $23(54.8)$ & \\
\hline $50-59$ & $\begin{array}{l}161 \\
(20.0)\end{array}$ & $76(47.2)$ & $85(52.8)$ & \\
\hline $60-69$ & $\begin{array}{l}357 \\
(44.3)\end{array}$ & $\begin{array}{l}180 \\
(50.4)\end{array}$ & $\begin{array}{l}177 \\
(49.6)\end{array}$ & \\
\hline$\geq 70$ & $\begin{array}{l}246 \\
(30.5)\end{array}$ & $\begin{array}{l}128 \\
(52.0)\end{array}$ & $\begin{array}{l}118 \\
(48.0)\end{array}$ & \\
\hline \multicolumn{4}{|l|}{ Marital status } & \multirow[t]{5}{*}{0.04} \\
\hline Currently married and living with spouse & $\begin{array}{l}593 \\
(73.6)\end{array}$ & $\begin{array}{l}281 \\
(47.4)\end{array}$ & $\begin{array}{l}312 \\
(52.6)\end{array}$ & \\
\hline Single & $38(4.7)$ & $26(68.4)$ & $12(31.6)$ & \\
\hline Not living with spouse /divorced & $30(3.7)$ & $16(53.3)$ & $14(46.7)$ & \\
\hline Widowed & $\begin{array}{l}145 \\
(18.0)\end{array}$ & $80(55.2)$ & $65(44.8)$ & \\
\hline \multicolumn{4}{|l|}{ Occupation } & \multirow{3}{*}{$\begin{array}{l}< \\
0.001\end{array}$} \\
\hline Retired & $\begin{array}{l}258 \\
(32.0)\end{array}$ & $95(36.8)$ & $\begin{array}{l}163 \\
(63.2)\end{array}$ & \\
\hline Unemployed/stays at home & $\begin{array}{l}140 \\
(17.4)\end{array}$ & $90(64.3)$ & $50(35.7)$ & \\
\hline
\end{tabular}

1. Diabetes-related distress is defined as stressful feelings associated with the challenges of managing diabetes and concerns related to diabetic complications. 


\begin{tabular}{|c|c|c|c|c|}
\hline \multirow[t]{3}{*}{ Characteristic } & \multirow[t]{3}{*}{ Overall } & \multicolumn{2}{|c|}{$\begin{array}{l}\text { Diabetes-related } \\
\text { distress }^{1}\end{array}$} & \multirow{3}{*}{$\begin{array}{l}p \\
\text { value } \\
\left(X^{2}\right. \\
\text { test })\end{array}$} \\
\hline & & \multirow{2}{*}{$\begin{array}{l}\text { YES } \\
\text { Number } \\
\text { (\%) }\end{array}$} & \multirow{2}{*}{$\begin{array}{l}\text { NO } \\
\text { Number } \\
(\%)\end{array}$} & \\
\hline & & & & \\
\hline Farmer & $\begin{array}{l}296 \\
(36.7)\end{array}$ & $\begin{array}{l}170 \\
(57.4)\end{array}$ & $\begin{array}{l}126 \\
(42.6)\end{array}$ & \\
\hline $\begin{array}{l}\text { Small trade/worker/government employee/private } \\
\text { company }\end{array}$ & $\begin{array}{l}112 \\
(13.9)\end{array}$ & $48(42.9)$ & $64(57.1)$ & \\
\hline Size of household & & & & 0.08 \\
\hline 5 members or more & $\begin{array}{l}218 \\
(27.0)\end{array}$ & $\begin{array}{l}111 \\
(50.9)\end{array}$ & $\begin{array}{l}107 \\
(49.1)\end{array}$ & \\
\hline 3-4 members & $\begin{array}{l}181 \\
(22.5)\end{array}$ & $82(45.3)$ & $99(54.7)$ & \\
\hline 2 members & $\begin{array}{l}318 \\
(39.5)\end{array}$ & $\begin{array}{l}155 \\
(48.7)\end{array}$ & $\begin{array}{l}163 \\
(51.3)\end{array}$ & \\
\hline 1 member (living alone) & $\begin{array}{l}89 \\
(11.0)\end{array}$ & $55(61.8)$ & $34(38.2)$ & \\
\hline Economic situation of household (self-reported) & & & & $<001$ \\
\hline Wealthy & $73(9.1)$ & $29(39.7)$ & $44(60.3)$ & \\
\hline Medium & $\begin{array}{l}638 \\
(79.2)\end{array}$ & $\begin{array}{l}303 \\
(47.5)\end{array}$ & $\begin{array}{l}335 \\
(52.5)\end{array}$ & \\
\hline Poor & $\begin{array}{l}95 \\
(11.8)\end{array}$ & $71(74.7)$ & $24(25.3)$ & \\
\hline Physical health (self-reported) & & & & $<001$ \\
\hline Excellent/Good & $\begin{array}{l}105 \\
(13.0)\end{array}$ & $28(26.7)$ & $77(73.3)$ & \\
\hline Fair & $\begin{array}{l}399 \\
(49.5)\end{array}$ & $\begin{array}{l}179 \\
(44.9)\end{array}$ & $\begin{array}{l}220 \\
(55.1)\end{array}$ & \\
\hline Poor & $\begin{array}{l}302 \\
(37.5)\end{array}$ & $\begin{array}{l}196 \\
(64.9)\end{array}$ & $\begin{array}{l}106 \\
(35.1)\end{array}$ & \\
\hline Duration of diabetes & & & & 0.28 \\
\hline$<5$ years & $\begin{array}{l}389 \\
(48.3)\end{array}$ & $\begin{array}{l}203 \\
(52.2)\end{array}$ & $\begin{array}{l}186 \\
(47.8)\end{array}$ & \\
\hline
\end{tabular}




\begin{tabular}{|c|c|c|c|c|}
\hline \multirow[t]{3}{*}{ Characteristic } & \multirow[t]{3}{*}{ Overall } & \multicolumn{2}{|c|}{$\begin{array}{l}\text { Diabetes-related } \\
\text { distress }^{1}\end{array}$} & \multirow{3}{*}{$\begin{array}{l}\mathrm{p} \\
\text { value } \\
\left(\chi^{2}\right. \\
\text { test) }\end{array}$} \\
\hline & & YES & NO & \\
\hline & & $\begin{array}{l}\text { Number } \\
\text { (\%) }\end{array}$ & $\begin{array}{l}\text { Number } \\
(\%)\end{array}$ & \\
\hline $5-10$ years & $\begin{array}{l}292 \\
(36.2)\end{array}$ & $\begin{array}{l}145 \\
(49.7)\end{array}$ & $\begin{array}{l}147 \\
(50.3)\end{array}$ & \\
\hline$>10$ years & $\begin{array}{l}125 \\
(15.5)\end{array}$ & $55(44.0)$ & $70(56.0)$ & \\
\hline
\end{tabular}

${ }^{1}$. Diabetes-related distress is defined as stressful feelings associated with the challenges of managing diabetes and concerns related to diabetic complications.

\section{Association between unmet needs for informal support and diabetes-related distress}

For two out of six types of unmet needs, increased odds (adjusted for household socio-economic status) of having DRD was observed if the person reported to have an unmet need than if not having an unmet need: unmet need for emotional support or financial support $(\mathrm{OR}=2.59, \mathrm{Cl} 95 \%: 1.19-5.63$ and $\mathrm{OR}=1.63$, Cl95\%: 1.10-2.40, respectively), while no associations were seen for the remaining types of unmet needs (Table 2). For an unmet need for emotional support or financial support, additional adjustment for selfreported physical health attenuated the odds slightly $(\mathrm{OR}=2.38, \mathrm{Cl} 95 \%: 1.09-5.24$ and $\mathrm{OR}=1.49, \mathrm{Cl} 95 \%$ : 1.00-2.23, respectively), while adjustment for household size and marital status did not influence the results (Table 2). 
Table 2

Associations between unmet needs for informal support and diabetes-related distress

\begin{tabular}{|c|c|c|c|c|}
\hline \multirow[t]{2}{*}{ Unmet needs for informal support } & \multirow{2}{*}{$\begin{array}{l}\text { Crude odds ratio } \\
\text { (Cl95\%) }\end{array}$} & \multirow{2}{*}{$\begin{array}{l}\text { Model } 1 \\
\text { Odds ratio } \\
\text { (Cl95\%) }\end{array}$} & \multirow{2}{*}{$\begin{array}{l}\text { Model } 2 \\
\text { Odds ratio } \\
\text { (CI95\%) }\end{array}$} & \multirow{2}{*}{$\begin{array}{l}\text { Model } 3 \\
\text { Odds ratio } \\
\text { (Cl95\%) }\end{array}$} \\
\hline & & & & \\
\hline \multicolumn{5}{|l|}{$\begin{array}{l}\text { Health care visits/transportation } \\
(n=402)\end{array}$} \\
\hline No (ref) & 1 & 1 & 1 & 1 \\
\hline Yes & $\begin{array}{l}1.57(1.11- \\
2.22)\end{array}$ & $\begin{array}{l}1.22(0.84- \\
1.76)\end{array}$ & $\begin{array}{l}1.14(0.78- \\
1.65)\end{array}$ & $\begin{array}{l}1.13(0.77- \\
1.65)\end{array}$ \\
\hline \multicolumn{5}{|l|}{ Remembering medication } \\
\hline No (ref) & 1 & 1 & 1 & 1 \\
\hline Yes & $\begin{array}{l}1.53(0.99- \\
2.35)\end{array}$ & $\begin{array}{l}1.27(0.82- \\
2.00)\end{array}$ & $\begin{array}{l}1.14(0.73- \\
1.80)\end{array}$ & $\begin{array}{l}1.14(0.72- \\
1.79)\end{array}$ \\
\hline \multicolumn{5}{|l|}{$\begin{array}{l}\text { Purchasing and preparing food } \\
(n=402)\end{array}$} \\
\hline No (ref) & 1 & 1 & 1 & 1 \\
\hline Yes & $\begin{array}{l}2.35(1.40- \\
2.93)\end{array}$ & $\begin{array}{l}1.62(0.95- \\
2.77)\end{array}$ & $\begin{array}{l}1.53(0.89- \\
2.65)\end{array}$ & $\begin{array}{l}1.53(0.88- \\
2.67)\end{array}$ \\
\hline \multicolumn{5}{|l|}{$\begin{array}{l}\text { Remembering to doing exercise } \\
(n=401)\end{array}$} \\
\hline No (ref) & 1 & 1 & 1 & 1 \\
\hline Yes & $\begin{array}{l}1.60(1.07- \\
2.38)\end{array}$ & $\begin{array}{l}1.36(0.90- \\
2.06)\end{array}$ & $\begin{array}{l}1.21(0.79- \\
1.84)\end{array}$ & $\begin{array}{l}1.19(0.78- \\
1.83)\end{array}$ \\
\hline \multicolumn{5}{|l|}{ Emotional support $(n=402)$} \\
\hline No (ref) & 1 & 1 & 1 & 1 \\
\hline Yes & $\begin{array}{l}3.65(1.72- \\
7.77)\end{array}$ & $\begin{array}{l}2.59 \\
5.63)\end{array}$ & $\begin{array}{l}2.38(1.09- \\
5.24)\end{array}$ & $\begin{array}{l}2.39 \\
5.33)\end{array}$ \\
\hline \multicolumn{5}{|l|}{$\begin{array}{l}\text { Financial support with any of the } \\
\text { above }(n=402)\end{array}$} \\
\hline No (ref) & 1 & 1 & 1 & 1 \\
\hline
\end{tabular}

Model 1: Adjusted for age, gender, household economic status

Model 2: Adjusted for age, gender, household economic status, physical health

Model 3: Adjusted for age, gender, household economic status, physical health, household size, marital status 


\begin{tabular}{|lllll|}
\hline Unmet needs for informal support & $\begin{array}{l}\text { Crude odds ratio } \\
\text { (Cl95\%) }\end{array}$ & $\begin{array}{l}\text { Model } 1 \\
\text { Odds ratio } \\
\text { (Cl95\%) }\end{array}$ & $\begin{array}{l}\text { Model 2 } \\
\text { Odds ratio } \\
\text { (Cl95\%) }\end{array}$ & $\begin{array}{l}\text { Model } 3 \\
\text { Odds ratio } \\
\text { (Cl95\%) }\end{array}$ \\
\hline Yes & $\begin{array}{l}2.07(1.43- \\
2.99)\end{array}$ & $\begin{array}{l}1.63(1.10- \\
2.40)\end{array}$ & $\begin{array}{l}1.49(1.00- \\
2.22)\end{array}$ & $\begin{array}{l}1.49(1.00- \\
2.23)\end{array}$ \\
\hline Model 1: Adjusted for age, gender, household economic status & & \\
\hline Model 2: Adjusted for age, gender, household economic status, physical health & \\
\hline $\begin{array}{l}\text { Model 3: Adjusted for age, gender, household economic status, physical health, household size, } \\
\text { marital status }\end{array}$
\end{tabular}

\section{Associations between number of unmet needs for informal support and diabetes-related distress}

Bivariate analysis showed that there was no association between 1 unmet need and DRD, but those with 2 or more unmet needs had higher odds of having DRD: 2 unmet needs: $\mathrm{OR}=1.77, \mathrm{Cl} 95 \%: 1.01-3.13,3$ unmet needs: $\mathrm{OR}=2.04, \mathrm{Cl} 95 \%$ : 1.11-3.73, and 4-6 unmet needs: $\mathrm{OR}=2.19, \mathrm{Cl}$ \%5: 1.23-3.87 (Table 3). After adjusting for age, sex, and household socio-economic status (Model 1); and self-reported health (Model 2); and marital status and number of co-residing household members (Model 3), the number of types of unmet needs was no longer associated with DRD (Table 3) 
Table 3

Associations between number of unmet needs for informal support and diabetes-related distress

\begin{tabular}{|c|c|c|c|c|}
\hline \multirow[t]{3}{*}{ Number of unmet needs } & \multirow{3}{*}{$\begin{array}{l}\text { Crude odds ratio } \\
\text { (Cl95\%) }\end{array}$} & \multirow{3}{*}{$\begin{array}{l}\text { Model } 1 \\
\text { Odd ratio } \\
\text { (Cl95\%) }\end{array}$} & \multirow{3}{*}{$\begin{array}{l}\text { Model } 2 \\
\text { Odds ratio } \\
\text { (Cl95\%) }\end{array}$} & \multirow{3}{*}{$\begin{array}{l}\text { Model } 3 \\
\text { Odds ratio } \\
\text { (Cl95\%) }\end{array}$} \\
\hline & & & & \\
\hline & & & & \\
\hline $\begin{array}{l}0 \text { unmet need }(n=546) \\
\text { (reference) }\end{array}$ & 1 & 1 & 1 & 1 \\
\hline 1 unmet need $(n=95)$ & $1.32(0.85-2.04)$ & $\begin{array}{l}1.12(0.72- \\
1.77)\end{array}$ & $\begin{array}{l}1.03(0.65- \\
1.64)\end{array}$ & $\begin{array}{l}1.03(0.65- \\
1.63)\end{array}$ \\
\hline 2 unmet needs $(n=55)$ & $1.77(1.01-3.13)$ & $\begin{array}{l}1.37(0.76- \\
2.47)\end{array}$ & $\begin{array}{l}1.29(0.71- \\
2.36)\end{array}$ & $\begin{array}{l}1.28(0.70- \\
2.35)\end{array}$ \\
\hline 3 unmet needs $(n=49)$ & $2.04(1.11-3.73)$ & $\begin{array}{l}1.86(0.99- \\
3.47)\end{array}$ & $\begin{array}{l}1.59(0.84- \\
3.00)\end{array}$ & $\begin{array}{l}1.59(0.84- \\
3.00)\end{array}$ \\
\hline $4-6$ unmet needs $(n=57)$ & $2.19(1.23-3.87)$ & $\begin{array}{l}1.49(0.82- \\
2.71)\end{array}$ & $\begin{array}{l}1.32(0.72- \\
2.41)\end{array}$ & $\begin{array}{l}1.30(0.70- \\
2.41)\end{array}$ \\
\hline \multicolumn{5}{|c|}{ Model 1: Adjusted for age, gender, household economic status } \\
\hline \multicolumn{5}{|c|}{ Model 2: Adjusted for age, gender, household economic status, physical health } \\
\hline $\begin{array}{l}\text { Model 3: Adjusted for age, } \\
\text { marital status }\end{array}$ & er, household & c status, & I health & old size, \\
\hline
\end{tabular}

\section{Discussion}

In this study, we found that $50.0 \%$ of adults with T2D in Thai Binh, Vietnam, had DRD. Prevalence of DRD varied by sex, marital status, occupation, economic situation of household, and physical health. Those with unmet needs for emotional support or financial support had higher odds of DRD than those with no unmet needs. The study also showed that ORs of DRD increased with increasing number of unmet needs, but after adjustments for socio-economic characteristics, the association was no longer statistically significant.

The prevalence of $50.0 \%$ DRD in our setting is higher than the prevalence of DRD in some Asian countries (18-27\%) [22], but lower than other Asian countries (54.5-63.7\%) [23], [24]. Factors such as demographic, socio-economic, biological, and behavioral characteristics are associated with differences in prevalence [25], which may explain the differences in DRD between Asian settings. In addition, in the present study, we assessed DRD through the short form of PAID 5 while other studies used the "Diabetes Distress Scale" [18, 22-24], "General Health Questionnaire", and a variety of other methods to access DRD [2], which may also have contributed to differences in DRD prevalence [20, 25-27].

Our findings of women having higher ORs of DRD than men are in line with studies from China [10], Italy [12], and South Africa [11]. Further, in our Vietnamese setting, the difference between men and women 
may be partly explained by marriage and kinship practices: due to marriage arrangements, women in Vietnam often move far away from their own family to live with their husband's family $[28,29]$. This could mean that they have fewer relatives to share difficulties with, including health related problems. Previous research has shown that living far from one's family can often generate feelings of loneliness and discomfort, making women more susceptible to distress [28-31]. Moreover, in Vietnam women are, more often than men, in charge of housework, and care of children and old people and other family members [28], which may also add to the feeling of distress.

Those who were unemployed or farmers had higher ORs of DRD than those working in small trade business/worker/government employee/private company, or those who were retired. Studies have shown that financial stress is associated with diabetes related costs such as medical expenses, travel expenses, and even daily activities, including costs for a particular diet [22]. In addition, a qualitative study from Thai Binh, Vietnam, found that patients with T2D feel "guilty" when they feel that their diabetes status influences their family's incomes and when they depend on others for help [30].

Five out of six types of unmet needs for informal support were associated with increased ORs of DRD. However, after adjusting for household socio-economic status, only unmet needs for emotional and financial support were associated with DRD suggesting that most needs are mediated by socio-economic status. Studies shows that emotional support is important for people with diabetes, especially for those with DRD: people with diabetes often want to get help and support in handling their feelings about diabetes [8,32]. Further, the more social support people with diabetes report to receive, including support in handling their feelings about diabetes, the less likely they are to report experiencing emotional distress [6]. A study in India showed that the lack of encouraging discussion with family and friends made DRD worse [4]. In terms of lack of financial support, other studies have found that patients with T2D can feel that they are a burden for the family, which may contribute to the DRD $[8,9]$.

The observed association between unmet needs for emotional or financial support and DRD may also reflect specific contextual family-related social characteristics - rather than a possible causal link between unmet needs for informal support and DRD. Being a member of a family with a low level of positive social interactions and thereby a concurrent high level of unmet needs for support may increase risk of DRD. If so, the observed association is more likely to mirror a link between family dysfunctional aspects and distress rather than contributing to an understanding of the role of unmet needs for support.

After adjustment for household socio-economic status, we did not find an association between unmet needs for transport and company when visiting health facilities, reminders to take medication, purchase and preparation of food, and reminders to engage in physical exercise, and DRD. In contrast, other studies found that reminders to take medication, diet maintenance, food preparation, support for getting adequate physical exercise, assistance for accessing health services, including transportation to the healthcare center, are significant informal support needs for diabetes control in people living with diabetes $[8,9]$. Another study showed that increase in social support was associated with high medication adherence [33], and it has been demonstrated that poor adherence to dietary advice and 
medications were associated with DRD [5]. Other studies showed that lower levels of DRD are seen in people who received social support for following a diet, taking medicine, and exercising [6, 7]. Lastly, a study from India showed that support from family in cooking most meals was significantly associated with lower triglycerides, HbA1c, and cholesterol [34], which are major predictors of DRD [24]. In our study, the people with T2D were outpatients at district hospitals, which in Vietnam means that they were not having severe diabetes-related complications and co-morbidities. Therefore, family members and relatives may have thought the person with T2FD are able to take care of themselves and not in need of informal support related to the needs assessed in this study.

Our findings showed that increasing number of unmet needs increased the ORs of DRD, which is in line with the result of the studies from other countries that demonstrated that increasing social support and satisfaction with these were associated with lesser DRD [7, 8, 35]. However, we also found that this association was influenced by the economic situation of the household in which the person with T2D lived.

A strength of this study is that it is the first quantitative study in Vietnam assessing DRD, and of the association between unmet needs for informal support and DRD. In addition, we had a high response rate (83.7\%). However, the study had some limitations. First, participants were recruited from the list of outpatients at three district hospitals in two districts in Thai Binh province. Therefore, we did not include inpatients, or outpatients from province hospitals, or the national referral hospital, where people with more severe diabetes receive treatment. Therefore, the prevalence of DRD in our study may be lower than if these patients been included. Second, unmet needs for informal support were assessed using six questions, whereas the associations between unmet needs for informal support and DRD may have had other dimensions, such as unmet needs for support for ordinary daily activities or unmet needs for guidance in performing self-management.

\section{Conclusions}

This study from Thai Binh, Vietnam, found that $50 \%$ of people living with diabetes have DRD. Unmet needs for emotional and financial support from family and/or relatives increased the odds of DRD. Thus, our research suggests that enhanced informal support may contribute to prevent or reverse DRD.

\section{Abbreviations}

DRD: Diabetes-related distress; T2D: type 2 diabetes; PAID 5: Problem Areas In Diabetes scale 5

\section{Declarations}

\section{Ethics approval and consent to participate}


The study followed ethical guidelines developed by CIOMS (Council for International Organization of Medical Sciences). Both oral and written informed consent were obtained from all research participants and confidentiality was guaranteed. Ethical approval of the project was granted by the Ethics Committee for Biomedical Research of Thai Binh University of Medicine and Pharmacy (decision 11/2018, 23rd November 2018).

\section{Consent for publication}

Not applicable

\section{Availability of data and materials}

The datasets used and/or analyzed during the current study are available from the corresponding author on reasonable request.

\section{Competing interests}

None

\section{Funding}

The present study is part of the interdisciplinary research project, Living Together with Chronic Disease: Informal Support for Diabetes Management in Vietnam (VALID) (17-M09-KU), funded by the Ministry of Foreign Affairs of Denmark (DANIDA)

\section{Authors' contributions}

All authors contributed to the development of data collection tools and training of interviewers. DKT participated in data collection and conducted the literature review and data analysis. DKT, IB, and JN developed the first version of the manuscript. JN, DWM and IB supervised the analyses. All authors contributed to subsequent revisions and editing of the manuscript.

\section{Acknowledgements}

We would like to thank DANIDA for funding this study. We also would like to thank the health authorities and health workers at all levels in Thai Binh for facilitating our work; special thanks go to village health workers from 8 communes in Thai Binh province for their support in collecting information. Lastly, our most sincere gratitude goes to all participants for taking part in this study. 


\section{Authors' information}

${ }^{1}$ Thai Binh University of Medicine and Pharmacy, 373 Ly Bon Street, Thai Binh city, Thai Binh, Viet Nam

2 Department of Anthropology, University of Copenhagen, Øster Farimagsgade 5, DK-1353 Copenhagen K, Denmark

${ }^{3}$ Research Unit for General Practice, Department of Public Health, University of South Denmark, Denmark

${ }^{4}$ Global Health Section, Department of Public Health, University of Copenhagen, Øster Farimagsgade 5, 1014, Copenhagen K, Denmark

${ }^{5}$ Emory Global Diabetes Research Center, Hubert Department of Global Health, Rollins School of Global Health, Emory University, Atlanta, GA, USA

\section{References}

1. Khue N T, Diabetes in Vietnam. Annals of Global Health, 2015. 81(6): p. 870-873.

2. Perrin N E, Davies M J, Robertson N, Snoek F J, and Khunti K, The prevalence of diabetes-specific emotional distress in people with Type 2 diabetes: a systematic review and meta-analysis. Diabet Med, 2017. 34(11): p. 1508-1520.

3. Polonsky W H, Anderson B J, Lohrer P A, Welch G, Jacobson A M, Aponte J E, et al., Assessment of diabetes-related distress. Diabetes Care, 1995. 18(6): p. 754-60.

4. Kalra S, Jena B, and Yeravdekar R, Emotional and Psychological Needs of People with Diabetes. Indian Journal of Endocrinology and Metabolism, 2018. 22: p. 696.

5. Misra R and Lager J, Predictors of quality of life among adults with type 2 diabetes mellitus. Journal of diabetes and its complications, 2008. 22(3): p. 217-223.

6. Fisher $L$, Glasgow $R E$, and Strycker $L A$, The relationship between diabetes distress and clinical depression with glycemic control among patients with type 2 diabetes. Diabetes Care, 2010. 33(5): p. 1034-6.

7. Baek R N, Tanenbaum M L, and Gonzalez J S, Diabetes burden and diabetes distress: the buffering effect of social support. Ann Behav Med, 2014. 48(2): p. 145-55.

8. Ramkisson S, Pillay B J, and Sibanda W, Social support and coping in adults with type 2 diabetes. African journal of primary health care \& family medicine, 2017. 9(1): p. e1-e8.

9. Kristianingrum N D, Wiarsih W, and Nursasi A Y, Perceived family support among older persons in diabetes mellitus self-management. BMC Geriatr, 2018. 18(Suppl 1): p. 304.

10. Qiu S, Sun H, Liu Y, Kanu J S, Li R, Yu Y, et al., Prevalence and correlates of psychological distress among diabetes mellitus adults in the Jilin province in China: a cross-sectional study. PeerJ, 2017. 5: p. e2869-e2869. 
11. Ramkisson S, Pillay B J, and Sartorius B, Diabetes distress and related factors in South African adults with type 2 diabetes. Journal of Endocrinology, Metabolism and Diabetes of South Africa, 2016. Vol 21, No 2 (2016) p. 33-36.

12. Rossi M C, Lucisano G, Pintaudi B, Bulotta A, Gentile S, Scardapane M, et al., The complex interplay between clinical and person-centered diabetes outcomes in the two genders. Health and Quality of Life Outcomes, 2017. 15(1): p. 41.

13. Koetsenruijter J, van Eikelenboom N, van Lieshout J, Vassilev I, Lionis C, Todorova E, et al., Social support and self-management capabilities in diabetes patients: An international observational study. Patient Education and Counseling, 2016. 99(4): p. 638-643.

14. Strom $J L$ and Egede $L E$, The impact of social support on outcomes in adult patients with type 2 diabetes: a systematic review. Current diabetes reports, 2012. 12(6): p. 769-781.

15. van Dam H A, van der Horst F G, Knoops L, Ryckman R M, Crebolder H F, and van den Borne B H, Social support in diabetes: a systematic review of controlled intervention studies. Patient Educ Couns, 2005. 59(1): p. 1-12.

16. Allen S M and Mor V, The prevalence and consequences of unmet need. Contrasts between older and younger adults with disability. Med Care, 1997. 35(11): p. 1132-48.

17. Nicolucci A, Kovacs Burns K, Holt R I G, Comaschi M, Hermanns N, Ishii H, et al., Diabetes Attitudes, Wishes and Needs second study (DAWN2 $\left.{ }^{\text {TM}}\right)$ : Cross-national benchmarking of diabetes-related psychosocial outcomes for people with diabetes. Diabetic Medicine, 2013. 30(7): p. 767-777.

18. Chew B-H, Vos R, Mohd-Sidik S, and Rutten G E H M, Diabetes-Related Distress, Depression and Distress-Depression among Adults with Type 2 Diabetes Mellitus in Malaysia. PLOS ONE, 2016. 11(3): p. e0152095.

19. Zhou H, Zhu J, Liu L, Li F, Fish A F, Chen T, et al., Diabetes-related distress and its associated factors among patients with type 2 diabetes mellitus in China. Psychiatry Res, 2017. 252: p. 45-50.

20. McGuire B E, Morrison T G, Hermanns N, Skovlund S, Eldrup E, Gagliardino J, et al., Short-form measures of diabetes-related emotional distress: the Problem Areas in Diabetes Scale (PAID)- 5 and PAID-1. Diabetologia, 2010. 53(1): p. 66-9.

21. Lee J S, The Unmet Needs of the Elderly with Diabetes in Home Health Care. Social Work in Health Care, 2007. 45(3): p. 1-17.

22. Gahlan D, Rajput R, Gehlawat P, and Gupta R, Prevalence and determinants of diabetes distress in patients of diabetes mellitus in a tertiary care centre. Diabetes Metab Syndr, 2018. 12(3): p. 333-336.

23. Bao H, Liu J, and Ye J, Influencing Factors of the Diabetes Distress among Chinese Patients with Type 2 Diabetes Mellitus. Psychiatr Danub, 2018. 30(4): p. 459-465.

24. Parsa $S$, Aghamohammadi $M$, and Abazari $M$, Diabetes distress and its clinical determinants in patients with type II diabetes. Diabetes \& Metabolic Syndrome: Clinical Research \& Reviews, 2019. 13(2): p. 1275-1279.

25. Fisher L, Mullan J T, Skaff M M, Glasgow R E, Arean P, and Hessler D, Predicting diabetes distress in patients with Type 2 diabetes: a longitudinal study. Diabet Med, 2009. 26(6): p. 622-7. 
26. Polonsky W H, Fisher L, Earles J, Dudl R J, Lees J, Mullan J, et al., Assessing psychosocial distress in diabetes: development of the diabetes distress scale. Diabetes Care, 2005. 28(3): p. 626-31.

27. Schmitt A, Reimer A, Kulzer B, Haak T, Ehrmann D, and Hermanns N, How to assess diabetes distress: comparison of the Problem Areas in Diabetes Scale (PAID) and the Diabetes Distress Scale (DDS). Diabetic Medicine, 2016. 33(6): p. 835-843.

28. Nanda P, Gautam MA, Verma R, Hong KT, Linh MTG, Puri M, et al., Study on Gender, Masculinity and Son Preference in Nepal and Vietnam. . Int Cent Res Women New Delhi India, 2012. http://www.researchgate.net/profile/Abhishek_Gautam5/publication/272356023_Study_on_GenderMasculinity_and_Son_Preference_in_Nepal_and_Vietnam/links/54e3016a0cf2edaea09473b7.pdf.

29. Tho Tran N, Nguyen H T T, Nguyen H D, Ngo T V, Gammeltoft T, Rasch V, et al., Emotional violence exerted by intimate partners and postnatal depressive symptoms among women in Vietnam: A prospective cohort study. PLoS One, 2018. 13(11): p. e0207108.

30. Al N T, Dieu B T H, Dung V T K, Hanh P T M, and Gammeltoft T M, Distress in diabetes patients: A study from Vietnam combining quantitative and qualitative methods. Vietnam Medical Journal 2019. 1.

31. Gammeltoft T M, Domestic Moods: Maternal Mental Health in Northern Vietnam. Med Anthropol, 2018. 37(7): p. 582-596.

32. Song Y, Song H-J, Han H-R, Park S-Y, Nam S, and Kim M T, Unmet needs for social support and effects on diabetes self-care activities in Korean Americans with type 2 diabetes. The Diabetes educator, 2012. 38(1): p. 77-85.

33. Bouldin E D, Trivedi R B, Reiber G E, Rosland A M, Silverman J B, Krieger J, et al., Associations between having an informal caregiver, social support, and self-care among low-income adults with poorly controlled diabetes. Chronic Illn, 2017. 13(4): p. 239-250.

34. Epple C, Wright A L, Joish V N, and Bauer M, The Role of Active Family Nutritional Support in Navajos' Type 2 Diabetes Metabolic Control. Diabetes Care, 2003. 26(10): p. 2829-2834.

35. Schiøtz M L, Bøgelund M, Almdal T, Jensen B B, and Willaing I, Social support and self-management behaviour among patients with Type 2 diabetes. Diabetic Medicine, 2012. 29(5): p. 654-661. 